\title{
Adenoacanthoma of the endometrium: morphological changes induced by human papillomavirus
}

\author{
W F Kealy, P G Annis, J A Barry, J M Hogan
}

\begin{abstract}
The observation of koilocyte-like features in the squamous epithelium of some endometrial adenoacanthomas prompted an investigation into a possible viral aetiology. These changes closely resemble those that occur in the ectocervical mucosa which are accepted as morphological evidence of human papillomavirus (HPV) infection. Sections of 87 hysterectomy specimens removed for endometrial carcinoma over 12 years, together with preoperative curettings, were reviewed for the presence of acanthomatous change and for appearances suggestive of HPV infection. The ages of the women ranged from 36 to 84 years, average age 62.6. Light microscopical examination showed koilocytosis, papillary formations, and intranuclear eosinophilic inclusions of both squamous and glandular epithelium in some tumours. Immunocytochemistry and DNA in situ hybridisation indicated the presence of HPV antigen in squamous and glandular cells, and perinuclear virus particles characteristic of HPV were seen on electron microscopical examination in those cells with nuclear inclusions.

HPV probably infects endometrial adenocarcinomas directly from the cervix but it is unlikely that it has an aetiological role. It is possible, however, that in addition to being a "passenger," the virus may stimulate squamous metaplasia in some adenocarcinomas of the endometrium and may also exert some influence on their behaviour.
\end{abstract}

Adenoacanthoma of the endometrium is a malignant epithelial tumour composed of both glandular and squamous elements in which the squamous component is histologically benign. ${ }^{1-4}$ The squamous parts of the tumours are considered to arise as a result of metaplastic glandular cells, ${ }^{5-9}$ but there is little agreement about the amount of squamous epithelium which should be present before an adenocarcinoma may be called an adenoacanthoma. ${ }^{10-17}$ We have been impressed by the fact that the squamous epithelium present in uterine adenoacanthomas often displays cytoplasmic vacuolation and koilocyte-like changes, the appearances of which resemble those produced by human papillomavirus (HPV) infection of ectocervical epithelium.
With this in mind, we reviewed the sections of all uterine carcinomas received in this laboratory over 12 years and attempted to establish the presence of HPV in those with a squamous component.

\section{Methods}

Sections of hysterectomy specimens removed for endometrial carcinoma between 1977 and 1988 inclusive were re-examined for the presence of a squamous component. The occurrence of squamous epithelium of benign histological appearance intimately mingling with the tumour, however small in amount, was accepted as evidence of acanthomatous change. Note was also taken of epithelial changes which might be ascribed to HPV infection, such as cytoplasmic vacuolation and koilocyte-like change. Sections of cervix, when present, were also reviewed for similar epithelial appearances and for the presence of squamous metaplasia. Preoperative endometrial curettings were also re-examined.

In two hysterectomy specimens showing adenoacanthoma of the endometrium multiple circumferential blocks of the total cervix were taken, which extended from the ectocervix to the lower uterine cavity, to ascertain whether there was a direct connection between cervical metaplastic epithelium and the endometrium. Immunohistochemistry for HPV was performed on sections of 23 adenoacanthomas and the accompanying cervix, and six endometrial curettings were also included. An immunoperoxidase method using a polyclonal antipapillomavirus antibody was used followed by visualisation with an avidin-biotin complex detection system (Dako). DNA in situ hybridisation for HPV was applied to sections of adenoacanthoma in 11 cases using biotinylated probes specific for HPV types 6/11, 16/18, and 30/50. (Enzo diagnostics).

In two instances the hysterectomy specimen was received fresh and unfixed and multiple random blocks of the endometrial carcinoma were taken into glutaraldehyde for electron microscopical examination. Selected areas of formalin fixed, paraffin wax embedded blocks of endometrial adenoacanthomas were also reprocessed for ultrastructural examination.

\section{Results}

Eighty seven hysterectomy specimens of endometrial carcinoma were received into this laboratory over the study period. Endometrial curettings before hysterectomy were sent for 
examination in 63 cases. Squamous epithelium was identified in sections of endometrial adenocarcinoma in 50 hysterectomy cases, 46 of which showed acanthomatous change (fig 1), four were examples of adenosquamous carcinoma. Koilocyte-like changes of the squamous epithelium were present in 28 adenoacanthomas (fig 2). These cellular changes occurred both superficially and deeply within the tumours. Keratinisation was not a feature of the squamous epithelium and multinucleation was rarely seen. In places the squamous and glandular cells adopted a rather papillary pattern. Round, relatively large, faintly eosinophilic nuclear inclusions were seen focally in both glandular and squamous epithelium (figs 3 and 4). Metastases from some of the endometrial carcinomas also showed focal benign squamous epithelium and occasionally koilocyte-like changes.

Four of the accompanying cervices showed a deficiency of ectocervix. Of the remaining 42 , 20 showed squamous metaplasia of the endocervical epithelium. Microscopic examination of sections of the multiple circumferential blocks taken from the whole cervix in the two cases showed focal squamous metaplasia, but direct extension of the squamous epithelium to the uterine cavity was not seen. Koilocytic change in the ectocervical epithelium was present in 13 cases and of these, 10 also showed squamous metaplasia. Intranuclear inclusion bodies of the type seen in the endometrium were not present in either the ectocervical or endocervical epithelium. Preoperative endometrial curettings were performed in 32 instances in those patients with adenoacanthoma. Seventeen of these showed acanthomatous change of which 12 had koilocytic features suggestive of HPV infection. Eosinophilic intranuclear inclusions were seen in some of the squamous cells of a small number of curettings.

\section{IMMUNOHISTOCHEMISTRY}

This technique for HPV showed positive staining in sections from 13 hysterectomies and one endometrial curetting. The staining was distributed in a rather focal manner, of varying intensity, and in places affected both the nucleus and cytoplasm of both squamous and glandular epithelium. No cytological features accounted for the variability of staining but the squamous epithelium tended to stain more intensely than the glandular cells. The intranuclear inclusions, however, tended to stain more darkly in the glandular epithelium (fig 5). Sections of cervix showed focal staining of both glandular and squamous cells. This positivity, however, was not often accompanied by similar staining of the endometrium and indeed, the converse was more usual. Immunoperoxidase staining of a single ovarian metastasis with squamous metaplasia was negative.

\section{DNA IN SITU HYBRIDISATION}

In sections of endometrial adenoacanthoma from 11 cases five tumours were negative for HPV. Three showed strong focal positivity for all the viral subtypes. The remaining three were negative for subtype $6 / 11$; of these, however, one showed positive staining of some squamous cells for subtype $16 / 18$ and another for $31 / 35 / 51$. The third showed positivity of occasional squamous and glandular cells for subtypes $16 / 18$ and $31 / 35 / 51$, respectively. The probe tended to stain the intranuclear inclusions only weakly but outlined the perinuclear area rather intensely (fig 6). In common with most endometrial adenoacanthomas, those tumours showing positive immunohisto-
Figure 1 Adenoacanthoma of endometrium showing benign squamous epithelium.

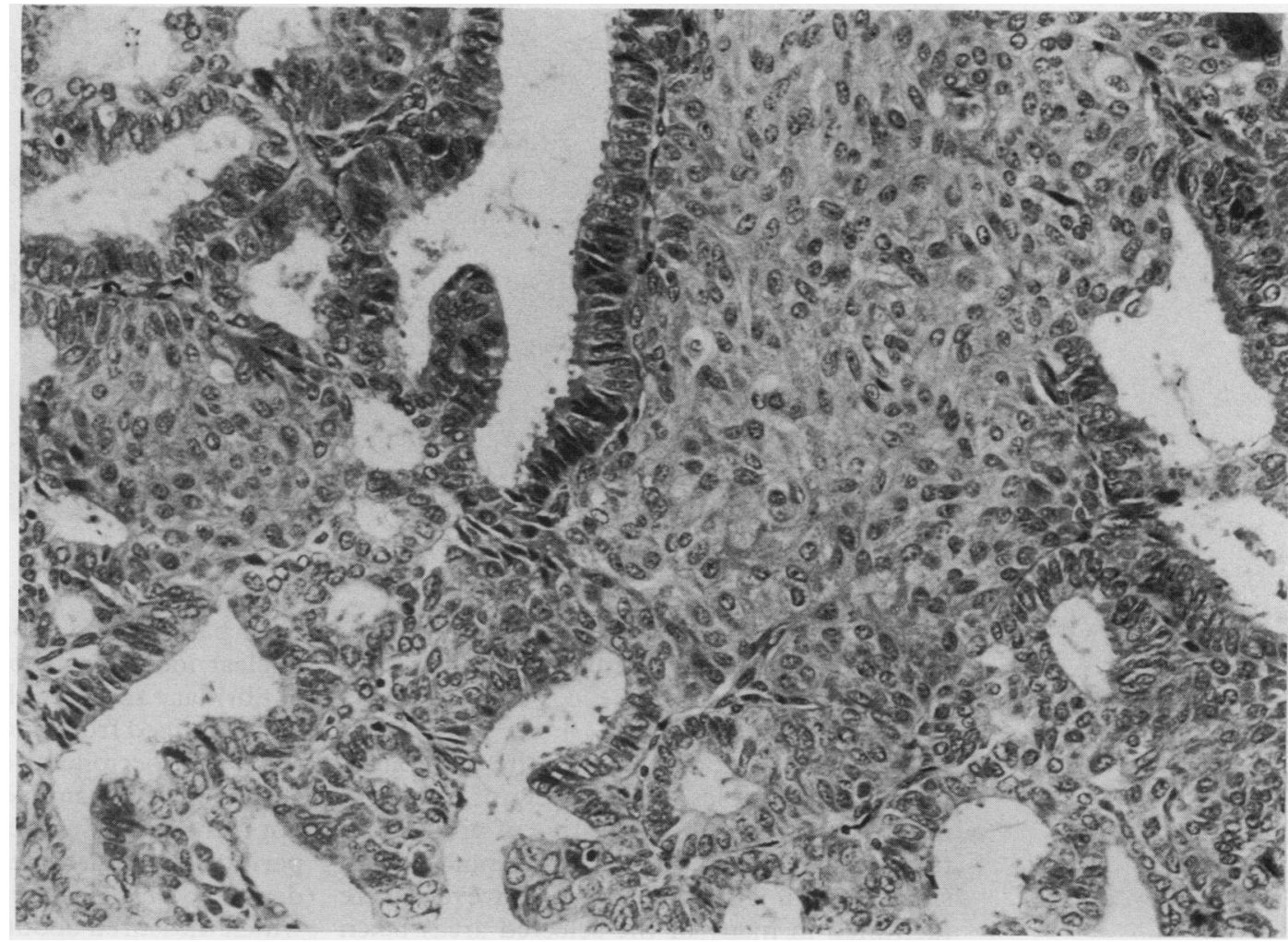


Figure 2 Adenoacanthoma of endometrium showing koilocyte-like change of squamous epithelium (Haematoxylin and eosin.

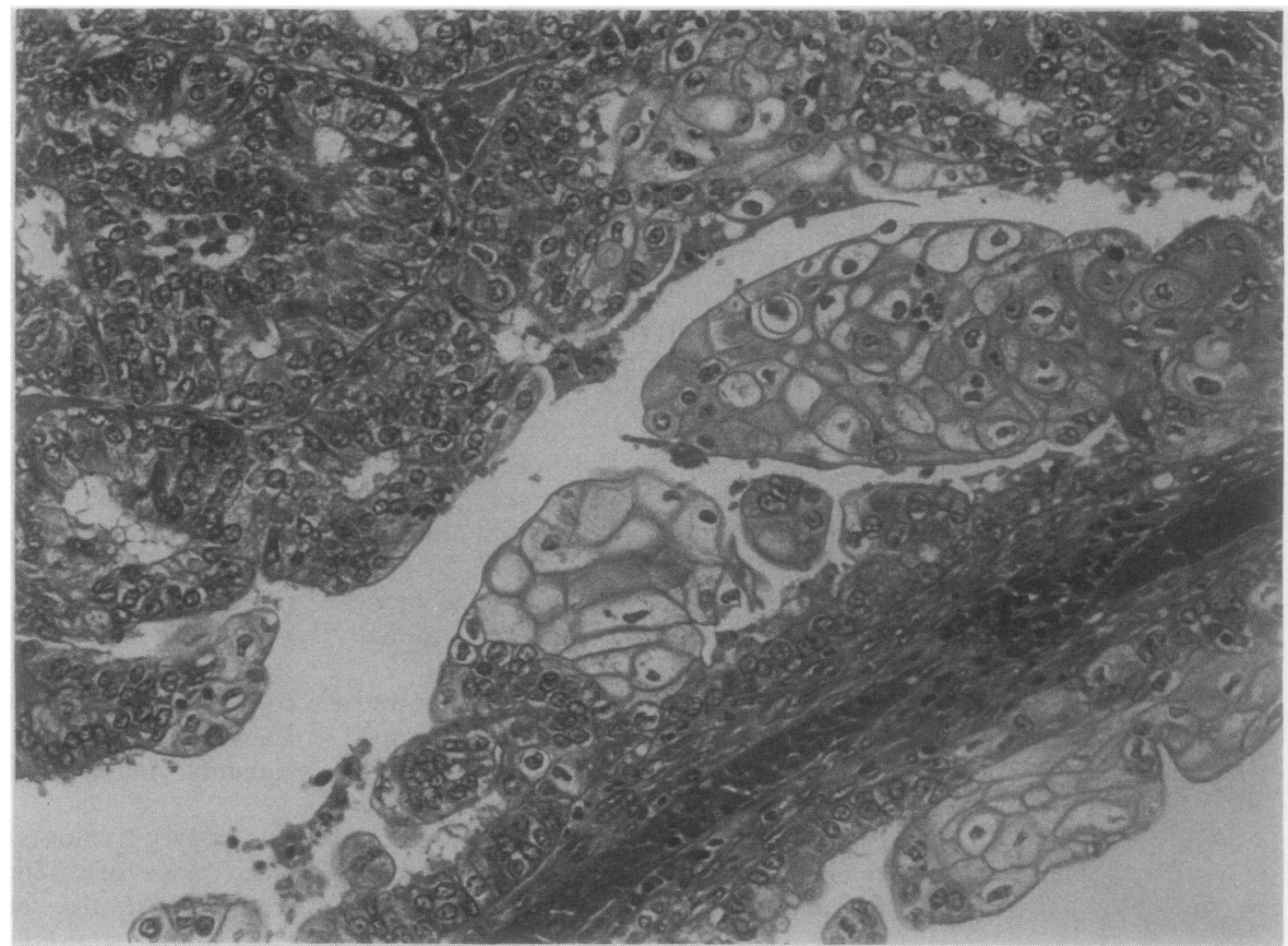

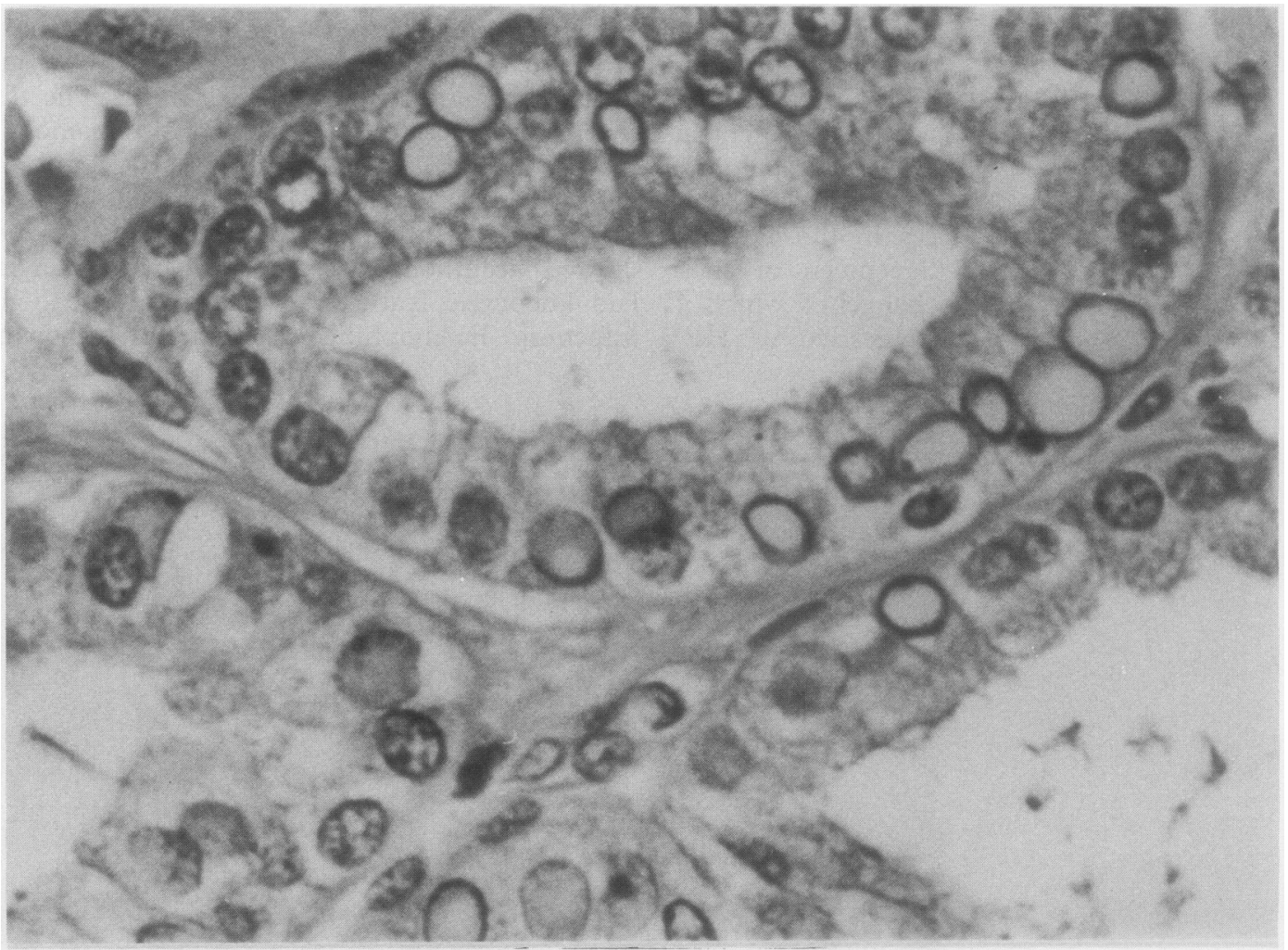

chemistry and DNA in situ hybridisation were all well differentiated carcinomas.

\section{ELECTRON MICROSCOPY}

Ultrastructural examination of the glutaraldehyde fixed samples showed few of the light microscopic features suggestive of viral infection, as described above. Appearances very suggestive of HPV infection, however, were identified in many of the selected areas taken from paraffin wax blocks. Examination of the nuclear inclusions showed that they consisted of fibrillary and granular material, the fibrils of which ranged from 5 to $10 \mathrm{~nm}$ in thickness and there was peripheral displacement of nuclear chromatin. Intranuclear viral particles were not identified. Many cells, however, contained perinuclear aggregates of spherical electron dense bodies, not membrane bound, each of which measured about $55 \mathrm{~nm}$ in diameter (figs epithelium with nuclear inclusions (Haematoxylin and eosin.) 
Figure 4 Squamous epithelium with nuclear inclusions (Haematoxylin and eosin.)
Figure 5 Adenoacanthoma of endometrium with positive staining of glandular and squamous nuclei. (HPV

Immunoperoxidase.)
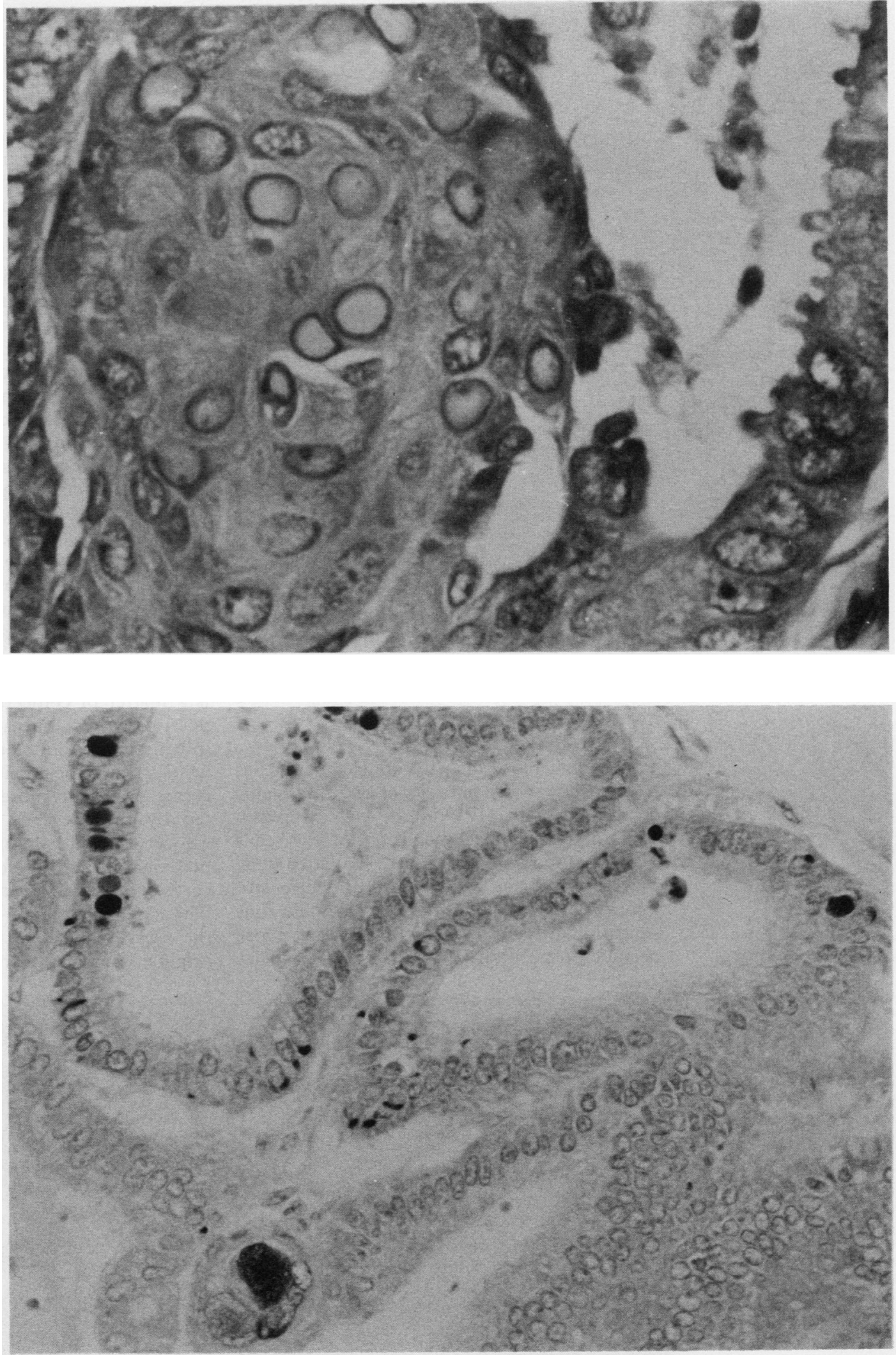

7 and 8). Tissue preservation was not ideal and prècise morphological analysis was therefore unsatisfactory. Nevertheless, the size of these structures and their arrangement in "rosary bead" and "mosaic" patterns were highly suggestive of papilloma virions.

koilocyte-like changes of the squamous epithelium of some adenoacanthomas and the presence of large intranuclear inclusions in both glandular and squamous cells suggest very strongly that the changes are due to viral infection. Positive staining for HPV antigen by the immunoperoxidase technique, together with its demonstration by DNA in situ hybridisation, confirms that it is present. UltraDiscussion

The light microscopic appearances of 


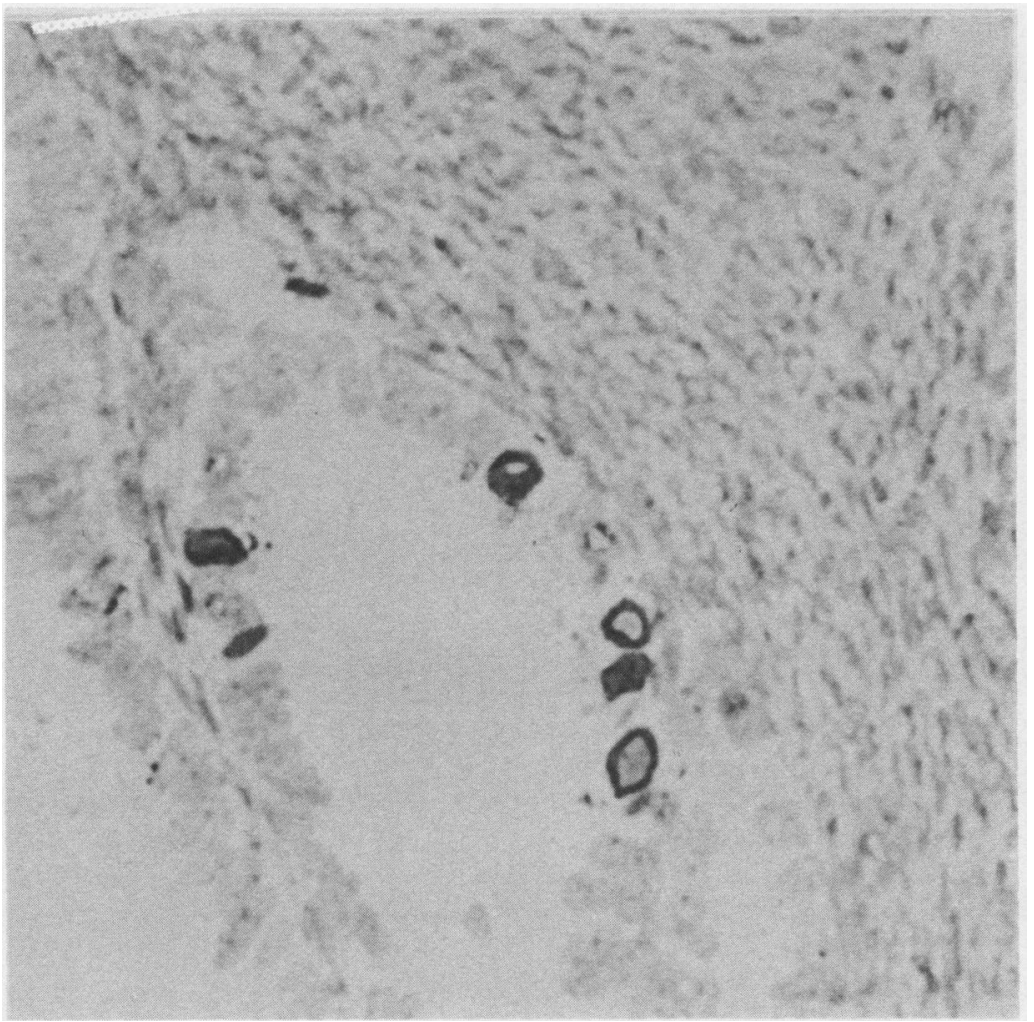

Figure 6 Glandular epithelium showing nuclear and perinuclear staining. (HPV DNA in situ hybridisation.)

Figure 7 Fibrillary/ granular nucleus with peripheral displacement of chromatin. Perinuclear nucleocapsids showing $a$ palisading "rosary bead" formation. although unable to show intranuclear virus, has nevertheless shown particles of a size and shape compatible with HPV in the cell cytoplasm adjacent to the nuclear membrane of those cells with intranuclear inclusions. This latter finding reinforces the appearances of the in situ hybridisation in which the nuclear inclusions stained faintly but where there was intense perinuclear positivity (fig 6). No virus particles were demonstrable inside the nuclear inclusions, but the peripheral condensation of nuclear chromatin and the presence of granular and fibrillary material were suggestive of viral infection. The intranuclear fibrils had an appearance similar to the type II fibrils described with early adenovirus infection ${ }^{18}$ and in these cases were possibly coupled with HPV antigen. The source of the squamous epithelium in adenoacanthomas of the endometrium is unclear but the cells most likely arise as a result of metaplasia either through squamous differentiation of a common stem cell, or of a glandular cell, and possibly instigated by oestrogens. ${ }^{3} 411$ 19-22

We could not show direct continuity between foci of squamous metaplasia of the endocervix and the endometrial cavity and this fact would tend to support the metaplastic origin of the benign squamous epithelium in adenoacanthomas. Equally, the finding that acanthomatous change was present in a large percentage of uterine curettings of the tumour obtained shortly before hysterectomy would militate against the possibility of implantation of squamous epithelium from the cervix and the stimulation of squamous metaplasia by the trauma of curettage.

The origin of HPV in endometrial carcinoma is a matter of conjecture and two routes are possible: direct spread from the cervix, or infection via the bloodstream. Both routes would seem to be possible, but spread from the cervix is probably more likely ${ }^{2324}$ and is supported by the presence of koilocytosis of the ectocervical epithelium and positive immunoperoxidase staining for HPV of the endocervical cells in a considerable number of cases. The converse situation - that is, colonisation of the cervix by spread from the endometrium originally infected through the bloodstream-

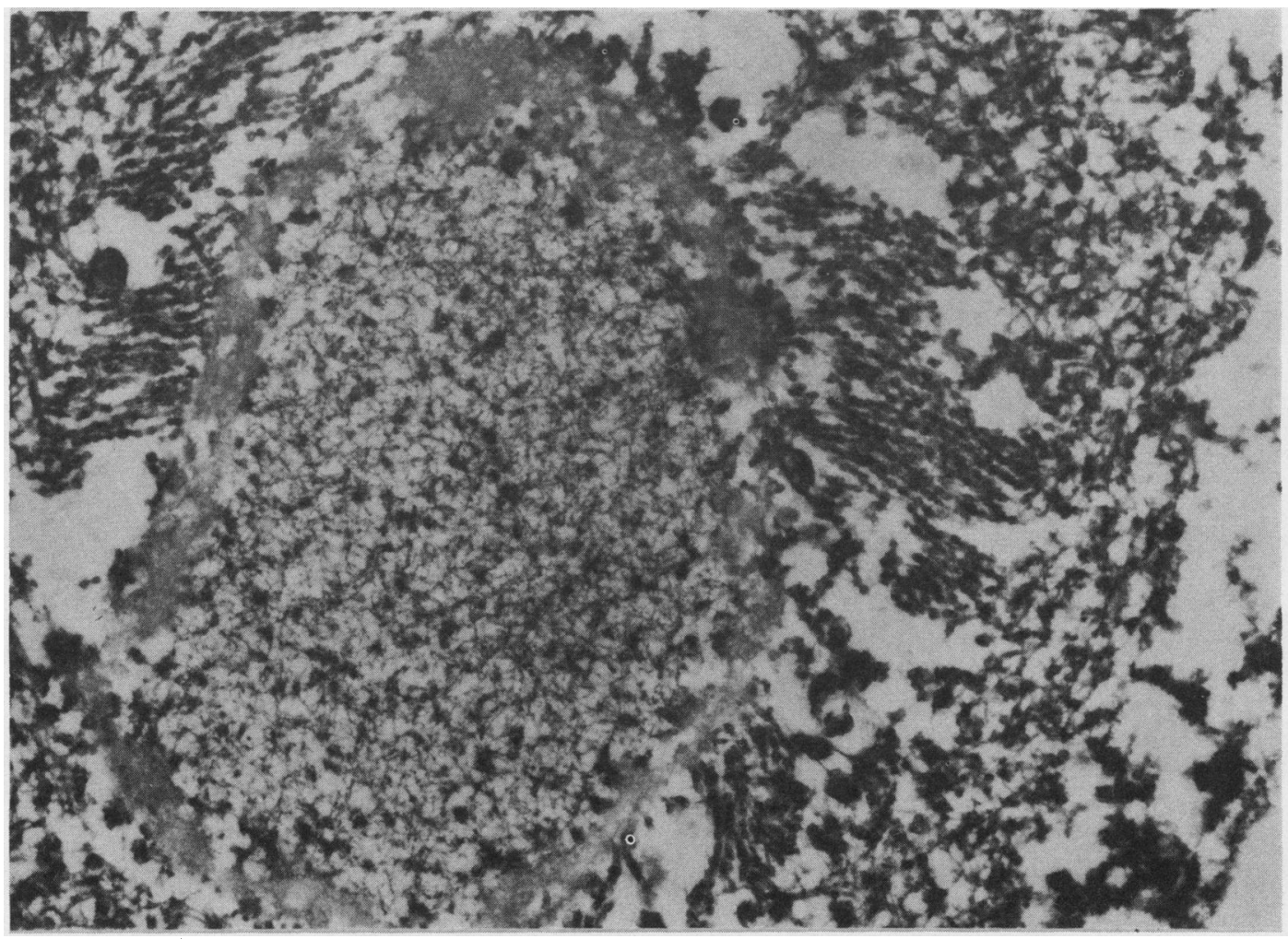


Figure 8 Fibrillary nucleus (bottom left) and perinuclear cytoplasmic virions about $50 \mathrm{~nm}$ in diameter.

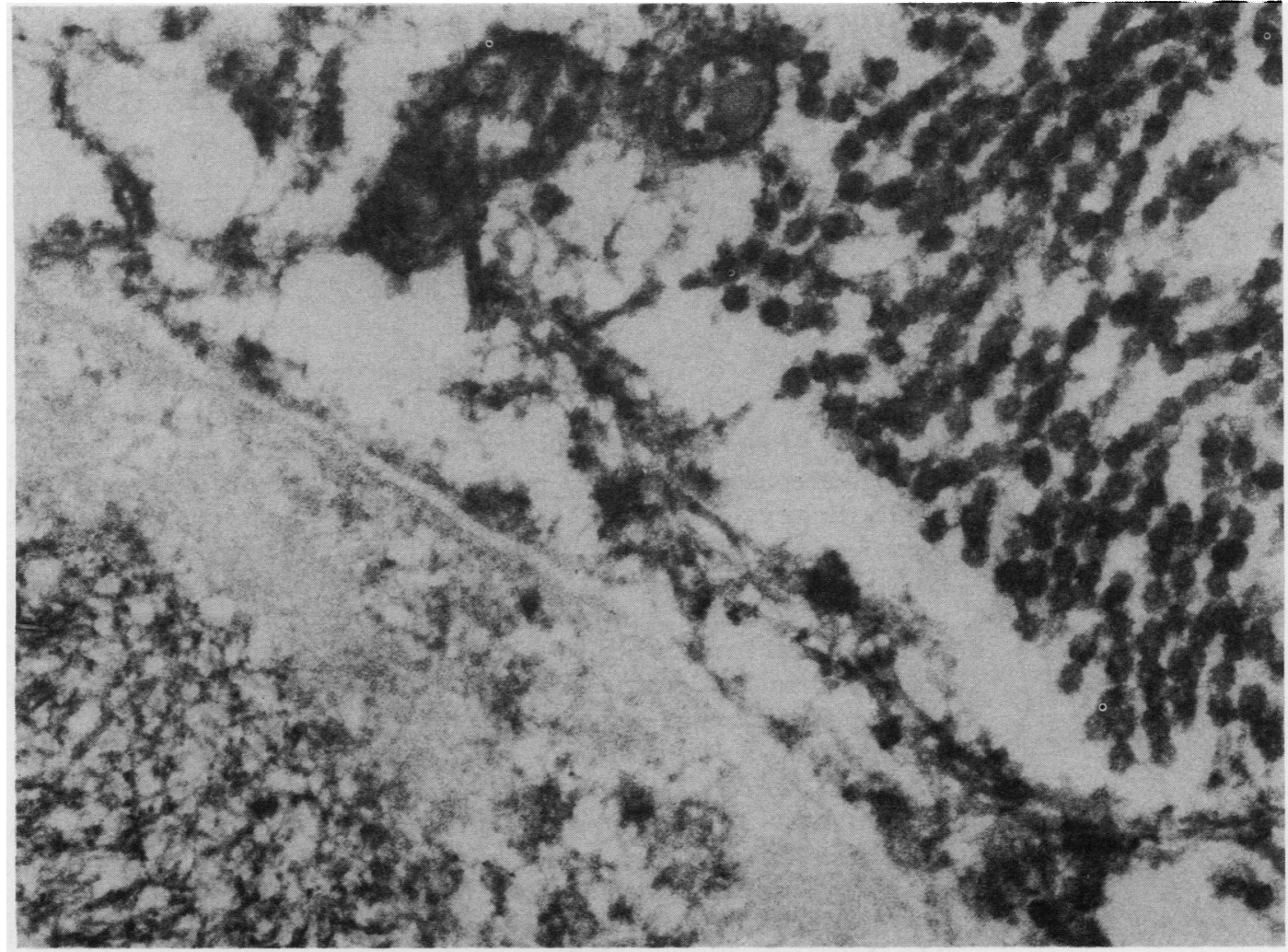

is unlikely, given the much more common HPV infection of the cervix.

Viruses have regularly been implicated in the genesis of tumours in both man and animals, and it is well known that HPV often infects the ectocervical epithelium and is closely associated with carcinoma of the cervix. ${ }^{22}{ }^{25} \mathrm{It}$ is unlikely, however, that the virus has any part in the pathogenesis of endometrial adenoacanthoma. It is more likely that it exists in the tumour as a passenger rather than an aetiological agent, although it may cause squamous metaplasia of the glandular epithelium in some cases. Whether the virus in any way influences the ultimate behaviour of the tumour is a consideration for investigation. What seems to be certain, however, is that the HPV does, from time to time, infect the epithelium of adenoacanthomas of the endometrium causing light microscopic and other changes which advertise its presence.

In this study we confined our attention to those endometrial carcinomas showing acanthomatous change as it was the koilocyte-like change in the squamous epithelium which first prompted the investigation. The finding of HPV infection of some of the glandular epithelium was unexpected and may form the basis of further study.

We thank Ms P Harte, who typed the script, Ms L O'Donovan for technical assistance, and the secretarial staff of the Southern Tumour Registry, Cork.

$1 \mathrm{Ng}$ ABP, Reagan JW, Storaasli JP, Wentz WB. Mixed adenosquamous carcinoma of the endometrium. Am J Clin Pathol 1972;59:765-81.

2 Salazar DM, DePapp EW, Bonfiglio TA, Feldstein ML, Rubin P, Rudolph JH. Adenosquamous carcinoma of the endometrium. Cancer 1977;40:119-30.

3 Barrowclough $\mathrm{H}$, Jaarsula KW. Adenoacanthoma of the endometrium: a separate entity or a histological curiosity? $J$ Clin Pathol 1980;33:1064-7.
4 Alberhasky RC, Connelly PJ, Christopherson WM. Carcinoma of the endometrium. IV. Mixed adenosquamous carcinoma. Am J Clin Pathol 1982;776:655-64.

5 Novak ER, Nalley WB. Uterine adenoacanthoma. Obstet Gynecol 1957;9:396-402.

6 Marcus SL. Adenoacanthoma of the endometrium. Am J Obstet Gynecol 1961;81:259-67.

7 Tweeddale DM, Early LS, Goodsitt ES. Endometrial adenoacanthoma. Obstet Gynecol 1964;23:611-9.

8 Morrison DL. Adenoacanthoma of the uterine body. Obstet Gynecol Br Commonwealth 1966;73:605-10.

9 Piver MS. Distant metastases of adenoacanthoma of the endometrium. Am J Obstet Gynecol 1966;96:1011-6.

10 Hopkin ID, Harlow RA, Stephens PJ. Squamous carcinoma of the body of the uterus. Br J Cancer 1970;24:71-6.

11 Liu CT. A study of endometrial adenocarcinoma with emphasis on morphologically variant types. Am J Clin 972:57.562-73.

12 Silverberg SG, Bolin HG, DeGiorgi LS. Adenoacanthoma and mixed adenosquamous carcinoma of the endometrium. Cancer 1972;30:1307-14

13 Aikawa M, Ng ABP. Mixed (adenosquamous), carcinoma of the endometrium; electron microscopic observations. Cancer 1973;31:385-97.

14 Haqqani MT, Fox $\mathrm{H}$. Adenosquamous carcinoma of the endometrium. J Clin Pathol 1976;29:959-66.

15 Blaustein A, Bigelow B, Demopoulos RI. Association of carcinoma of the breast with adenosquamous carcinoma of endometrium. Cancer 1978;42:326-9.

16 Christopherson WM. The significance of the pathologic findings in endometrial cancer. Clinics in obstetrics and findings in endometrial cancer. Clinics in obstetrics and
gynaecology. Philadelphia: WB Saunders, 1986:679-82.

17 Badib AO, Kurohara SS, Vongtama VY, Selim MA, Webster JH. Biologic behaviour of adenoacanthoma of the endometrium. Am J Obstet Gynecol 1970;106:205-9.

18 Martinex-Palomo A, Le Buis J, Bernard W. Electron microscopy or adenovirus 12 replication. J Virol 1967; $1: 817$.

19 Seltzer V, Klein M, Beckman $M$. The occurrence of squamous metaplasia as a precursor of squamous cell carcinoma of the endometrium. Obstet Gynecol 1977;49: 34S-7S.

20 Kanbour AI, Stock RJ. Squamous cell carcinoma in-situ of the endometrium and fallopian tube as superficial extension of invasive cervical carcinoma. Cancer 1978;42:570-9.

21 Lauchlan SC. Metaplasias and neoplasias of Mullerian

22 Hausen HZ. Papilloma viruses in human cancer. Cancer 1987;59:1692-6

23 Gupta JW, Saito K, Saito A, Fu YS, Shah KV. Human papillomavirus and the pathogenesis of cervical neoplasia. Cancer 1989;64:2104-10.

24 Roberts PF, Carron Brown J. Condylomatous atypia of the endometrial cavity. Case report to Br J Obstet Gynaecol 1985;92:535-8.

25 Drake M, Medley G, Mitchell H. Cytologic detection of HPV infection. Obstet Gynecol Clin North Am 1987;14:431. epithelium. Histopathol 1984;8:543-57. 